\title{
Jornalismo
}

\section{A produção de sentidos no telejornalismo: a saúde pública e o mito em Roland Barthes}

The creation of meaning in television journalism: public health and the myth Roland Barthes

FLORENTINA DAS NEVES SOUZA

Professora do Programa de Mestrado em Comunicação da Universidade Estadual de Londrina (UEL) - Londrina, PR, Brasil.

<flora@uel.br>

REINALDO CÉSAR ZANARDI

Professor do curso de Jornalismo da Universidade Norte do Paraná (Unopar) - Londrina, PR, Brasil. $<$ reinaldo.zanardi@unopar.br>

\section{RESUMO}

A imagem, como superfície que representa o mundo, fornece elementos para a constituição do mito a partir da fala selecionada em um contexto histórico-social-ideológico. $\mathrm{O}$ mito, como fala, está atrelado de tal forma à linguagem que precisa desta para a sua constituição. Roland Barthes defende que o mito é uma fala, e, este é o ponto de partida deste artigo que tem como objetivo discutir o mito e suas estruturas, usando como exemplos reportagens sobre a saúde pública, veiculadas no Jornal Nacional (JN), em 2011. O corpus do trabalho considera 42 reportagens, com um total de 133 minutos e 49 segundos. O resultado mostra que o enfoque das reportagens é predominantemente negativo. Superlotação, longa fila de espera, demora e falta de atendimento, peregrinação, são falas selecionadas pelo JN que ajudam a construir o mito da ineficiência da saúde pública no país.

Palavras-chave: Jornal Nacional; Mito; Saúde pública.

\section{ABSTRACT}

The image as a surface representing the world provides elements for the creation of the myth from the talks, selected in a sociohistorical context and ideological. The myth, like speech, is so tied to the language you need this for your constitution. Roland Barthes argues that myth is a speech and this is the starting point of this article is to discuss the myth and its structures, using as examples reports on public health, conveyed in the Jornal Nacional (JN), Rede Globo, in 2011. The corpus of work considered 42 reports with a total of 133 minutes and 49 seconds. The result shows that the focus of the reports is predominantly negative. Overcrowding, long waiting, delay and lack of care, pilgrimage lines are selected by JN that help build the myth of the inefficiency of public health in the country.

KeYwords: Jornal Nacional; Myth; Public health. 


\section{mito e suas estruturas}

Falar em mito pelo senso comum é falar de coisas - pessoas, situações e acontecimentos - que, pelo seu significado, geram uma aura que cria significados diversos. Neste caso, o mito, independente da realidade que o cerca, é alçado a uma condição extraordinária, que não pertence ao mundo dos mortais, sejam pelos valores inerentes, sejam pelos valores agregados, num processo que os veículos de comunicação de massa têm grande responsabilidade. $\mathrm{O}$ mito, portanto, envolve aspectos que passam pela noção de realidade e ficção, mas também, de crenças e simbologias pessoais e/ou coletivas.

Estudar o mito é optar por uma das correntes de estudo presentes entre os pesquisadores da área. Uma dessas correntes estuda a construção do mito, a partir da linguagem, ou seja, o mito constituído no processo de interação entre os indivíduos e os segmentos a que pertencem.

Roland Barthes é um dos nomes de maior expressão nesta corrente e que chega a afirmar que o "mito é uma fala". Uma fala entendida como signo, seja linguístico (oral e textual), ou visual. Afinal, a informação é construída num processo que envolve a língua, e, principalmente, a linguagem, ou seja, o exercício prático do código linguístico.

Outra corrente estuda o mito numa concepção antropológica, que faz interface principalmente com a religião. Nesta, o sagrado e o sobrenatural ocupam posição de destaque e são fundamentais para entender a relação dos indivíduos de uma comunidade com os seus mitos, seja no presente seja no passado. Neste sentido, as comunidades indígenas têm posição de destaque, visto que muitos autores se debruçam nesta perspectiva. Autores como Mircea Eliade, Ernst Cassirer, Claude Lévi-Strauss, Roberto Cardoso de Oliveira, Roberto da Matta, Eudoro de Souza e Joseph Campbell.

A criação de mitos na sociedade está vinculada diretamente à imagem, visto que este elemento reflete e condensa os processos culturais, inclusive, apoiados pelos 
veículos de comunicação. Assim, este artigo toma emprestado o conceito de Vilém Flusser que define imagem como uma superfície que pretende representar alguma coisa, algo que está no espaço e no tempo.

Para o autor, as imagens "são códigos que traduzem eventos em situações, processos em cenas. Não que as imagens eternalizem eventos; elas substituem eventos por cenas." (Flusser, 2002, p. 8). Para o autor, as imagens são mediações entre o homem e o mundo já que tem por objetivo representar o próprio mundo, mas que ao fazer esse movimento, as imagens interpõem-se entre o homem e o mundo. Aqui cabe um questionamento pertinente. Seria a relação imagem/homem/mundo o componente básico para a criação de mitos?

O homem, ao invés de se servir das imagens em função do mundo, passa a viver em função de imagens. Não mais decifra as cenas da imagem como significados do mundo, mas o próprio mundo vai sendo vivenciado como conjunto de cenas. [...] O homem se esquece do motivo pelo qual as imagens são produzidas; servirem de instrumentos para orientá-lo no mundo."

(Flusser, 2002, p. 9)

Nessa discussão, esse estudo adota como pano de fundo o livro Mitologias, escrito na década de 1950. Nele, Barthes reúne um conjunto de textos em que aborda os mitos da sociedade francesa. Passadas algumas décadas, a obra continua atual, visto que o processo do mito, defendido por Barthes, é construído num contexto histórico-social no qual a linguagem tem papel fundamental. 
Mesmo partindo de Barthes e seu livro Mitologias, esse artigo considera as importantes contribuições dadas pela corrente que estuda o mito na perspectiva antropológica, até porque, neste viés, também é levado em conta a interação dos indivíduos na sociedade na qual se inserem. E esse processo fornece importantes indicadores para entender a construção dos mitos atuais.

Barthes escreveu os textos que compõem o livro Mitologias entre 1954 e 1956, tendo sido publicados originalmente com o título Mythologies, em 1957. O texto de interesse direto nessa discussão é O mito é uma fala, escrito pelo autor em 1956. Barthes (1993, p. 131) afirma que o mito como fala "não é uma fala qualquer. São necessárias condições especiais para que a linguagem se transforme em mito". E por necessitar da linguagem e de condições especiais é que o autor define o mito como sistema de comunicação, uma mensagem.

O mito como sistema de comunicação, defendido por Barthes, encontra respaldo nos estudos da própria língua. Ataliba T. Castilho (2004, p. 11) lembra que existem três grandes modelos de teoria para a interpretação da linguagem. A primeira é a que toma a língua como atividade mental, que a reconhece como uma capacidade inerente ao ser humano. A segunda postula a língua como estrutura, num sistema composto de signos. A terceira teoria trata a língua como atividade social, por meio da qual as pessoas veiculam informações, externam sentimentos e agem sobre o outro.

As três correntes transformam a língua no patrimônio de uma população e esse patrimônio pode ser entendido do ponto de vista sociocultural, trazendo características desenvolvidas e moduladas ao longo dos tempos. E, neste sentido, os modelos apontados por Castilho fornecem pistas, que ajudam a entender as estruturas que compõem o mito como uma fala.

A língua, portanto, pressupõe um fenômeno natural ao ser humano, que lhe permite apreender os conteúdos, dando-lhes significados, que dependem de uma 
série de fatores como, o contexto histórico-social-ideológico dos envolvidos na situação.

O mito não se define pelo objeto da sua mensagem, mas pela maneira como a profere [...] Logo tudo pode ser mito? Sim, julgo que sim, pois o universo é infinitamente sugestivo. Cada objeto do mundo pode passar de uma existência fechada, muda, a um estado oral, aberto à apropriação da sociedade, pois nenhuma lei, natural ou não, pode impedir-nos de falar das coisas."

(Barthes, 1993, p. 131)

A sociedade apropria-se de muitas coisas, que lhe pertence ou não, porque essas podem fazer parte do seu repertório pessoal e/ou coletivo. Falar das coisas também implica em tomar como sua, a fala de terceiros. E neste processo, a fala - processada - toma nova configuração num processo constante que envolve interatividade mútua.

Mircea Eliade (2010, p. 8) ocupa-se dos mitos na perspectiva antropológica e reconhece que o mito "fornece os modelos para a conduta humana, conferindo, por isso mesmo, significação e valor à existência”. E são esses significados e valores conferidos à existência humana que tornam os mitos, seja na perspectiva antropológica, seja pelo viés da linguagem, um objeto de estudo de muita complexidade, que permite interpretações diversas em perspectivas que se complementam. 


\section{Objetivo e corpus}

Este artigo tem como objetivo discutir o papel do mito na perspectiva anunciada por Roland Barthes, associando-o aos veículos de comunicação, notadamente a Rede Globo e o seu principal telejornal, o Jornal Nacional (JN), em reportagens sobre a saúde pública brasileira, tendo como foco o Sistema Único de Saúde (SUS). Este é o programa nacional responsável por planejar e executar a política para saúde, seja na prevenção, seja na promoção da saúde, seja na cura e reabilitação. As reportagens têm como foco ações de assistência à saúde, na qual os pacientes buscam atendimento em unidades básicas, os chamados postos de saúde, e as unidades hospitalares.

O corpus que compõe este artigo considera o escopo da dissertação de Reinaldo César Zanardi, sob a orientação da professora Florentina das Neves Souza, no Programa de Mestrado em Comunicação da Universidade Estadual de Londrina (UEL). O levantamento de dados compreende 42 matérias sobre a saúde pública, veiculadas pelo Jornal Nacional (JN) durante o ano de 2011.

Flávio Porcello e Débora Lapa Gadret (2010) discutem o papel do telejornalismo e sua capacidade de auxiliar na formação da opinião pública e, por consequência, na formação da imagem pública dos atores políticos do país. Esse conceito - aplicado à política - pode ser estendido para outros objetos de estudo, visto que, o processo de construção da opinião pública pelo telejornalismo, obedece ao mesmo padrão.

Defende-se que as notícias veiculadas nos telejornais, que constroem enquadramentos sobre a realidade social através de recursos verbais e visuais, são resultados de uma disputa de forças entre jornalistas com seus códigos deontológicos, empresas de comunicação e suas estruturas organizacionais e, por fim, interação com outros campos, em especial, o campo político - todos imersos em uma cultura."

(Porcello; Gadret, 2010, p. 215) 
As reportagens do JN foram classificadas conforme a categoria, em sete divisões: Atendimento Médico Hospitalar; Programa/Projeto de Saúde; Saúde Complementar; Atendimento Médico Ambulatorial; Medicamentos; Morte por Doenças e Financiamento da Saúde.

As reportagens, também, foram classificadas a partir do método das valências, desenvolvido pelo Laboratório de Pesquisa em Comunicação Política e Opinião Pública (Doxa), criado em 1996, pelo Instituto Universitário de Pesquisas do Rio de Janeiro (IUPERJ), da Universidade Cândido Mendes. Em julho de 2010, o Doxa foi transferido para o Instituto de Estudos Sociais e Políticos (IESP) da Universidade Estadual do Rio de Janeiro (UERJ). Emprestando a técnica desenvolvida pelo Doxa, este estudo considera como:

1. "Valência Positiva": as matérias que destacam programas, projetos e ações de saúde que apresentam melhorias na qualidade de vida da população, no acesso aos serviços de saúde, na proteção aos direitos do usuário do sistema.

2. "Valência Negativa": incorpora as matérias que evidenciam aspectos problemáticos e conflituosos da saúde pública, como a falta de assistência, a falta de investimentos, a demora no atendimento e a deficiência estrutural dos serviços públicos de saúde sejam eles municipais, estaduais ou federais.

3. "Valência Neutra": formada por matérias que limitam a informar, sem juízo de valor ou crítica, as ações que envolverem a saúde pública, bem como a apresentação de dados numéricos relativos ao setor.

4. "Valência Equilibrada": trata de matérias que apresentam, em igual proporção, aspectos positivos e negativos referentes ao sistema público de saúde, independentemente do enfoque: ambulatorial, hospitalar, programas e projetos preventivos, promocionais ou curativos. 


\section{O mito criado na realidade}

Do total de matérias sobre a saúde pública, veiculadas em 2011, no Jornal Nacional, a categoria que apresenta o maior número é a de "Atendimento Médico Hospitalar", com 28 ocorrências, ou seja, 66,66\% do total. (Fig. 1). Em segundo lugar, está a categoria "Programa/Projeto de Saúde", com 8 ocorrências (19,04\%), seguida da categoria "Saúde Complementar" (2 ou 4,76\%). As demais categorias: "Atendimento Médico Ambulatorial", "Medicamentos", "Morte por Doenças" e "Financiamento da Saúde", tiveram - cada - uma ocorrência ou 2,38\%.

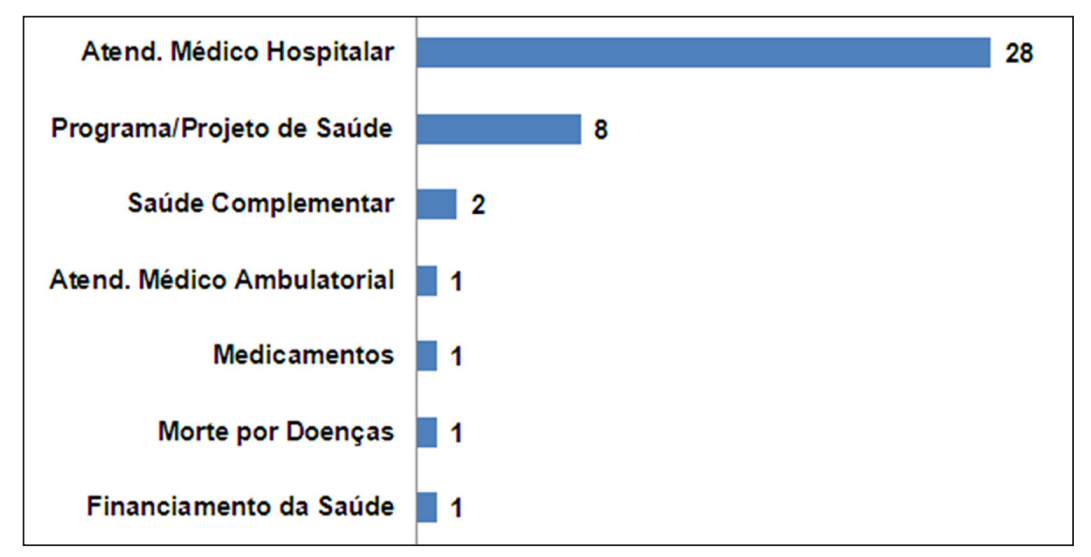

Figura 1 - Total de matérias veiculadas no Jornal Nacional (2011), conforme a categoria

A categoria "Atendimento Médico Hospitalar" responde por mais da metade das reportagens de saúde pública veiculadas pelo Jornal Nacional no período estudado. Isso pode ser explicado por vários fatores. Uma das explicações pode ser o fato de o atendimento hospitalar compreender pacientes que estão em situação 
limítrofe como saúde e doença, dor e sofrimento, vida e morte necessitando de assistência médica.

Este é um momento que pode criar conflitos se o paciente busca atendimento e não consegue. Quando a assistência à saúde do paciente não ocorre de forma adequada, existe o desgaste da relação serviço/paciente podendo provocar reclamações no atendimento, via veículos de comunicação.

Além disso, outro fator é o da factualidade, critério de noticiabilidade usado com frequência pelos jornalistas para definir o que é notícia e o que deve ser veiculado. A superlotação dos hospitais, verificada a partir da fila de espera ou da demora do atendimento, tem um componente factual muito importante que acaba chamando a atenção dos veículos de comunicação, que designam equipes para acompanhar as reclamações dos usuários.

Para Eliade (2010, p. 11) o mito envolve uma realidade bastante complexa, cujo processo de construção pode ser interpretado a partir de múltiplas perspectivas, mas sendo "sempre, portanto, a narrativa de uma "criação": ele relata de que modo algo foi produzido e começou a ser".

Assim, a narrativa dos telejornais gera muitos sentidos aos telespectadores, os quais conferem significados conforme suas próprias experiências.

A imagem que a mídia constrói da realidade é resultado de uma atividade profissional de mediação vinculada a uma organização que se dedica basicamente a interpretar a realidade social e mediar os que fazem parte do espetáculo mundano e o público."

(Vizeu; Correia, 2008, p. 13) 
Eliade afirma que o mito é uma criação e, como tal é, portanto, produzido artificialmente. Se foi produzido, pode ter relação direta com a realidade, ou não. Por isso, o mito, neste sentido, também se serve da ficção, afinal as falas não - necessariamente - estão comprometidas com a verdade absoluta dos acontecimentos, principalmente, no jornalismo em que a noção de verdade está vinculada à versão dos fatos contada por diferentes fontes. Não que a ficção seja uma mentira, uma não-verdade. Se partirmos da ficção, como interpretação da realidade, um mesmo acontecimento pode ter significados diferentes, dependendo de quem os assiste.

O material do mito é o material da nossa vida, do nosso corpo, do nosso ambiente; e uma mitologia viva, vital, lida com tudo isso nos termos que se mostram mais adequados à natureza do conhecimento da época. [...] Cada pessoa, ao nascer, é como um pedaço de papel em branco. [...] Logo depois do nascimento, porém, a sociedade começa a imprimir sua marca nessa criatura."

(Campbell, 1990, pp. 7-8)

Neste contexto, é importante considerar que as 42 reportagens do JN, de 2011, sobre a saúde pública, somam 133'49', ou seja, 2 horas, 13 minutos e 49 segundos. Desde total, a maioria do tempo, $83^{\prime} 02^{\prime \prime}$, é dedicada ao tema saúde pública sendo classificada como valência negativa (Fig. 2), a partir dos métodos desenvolvidos pelo Doxa e adaptados para este artigo. 


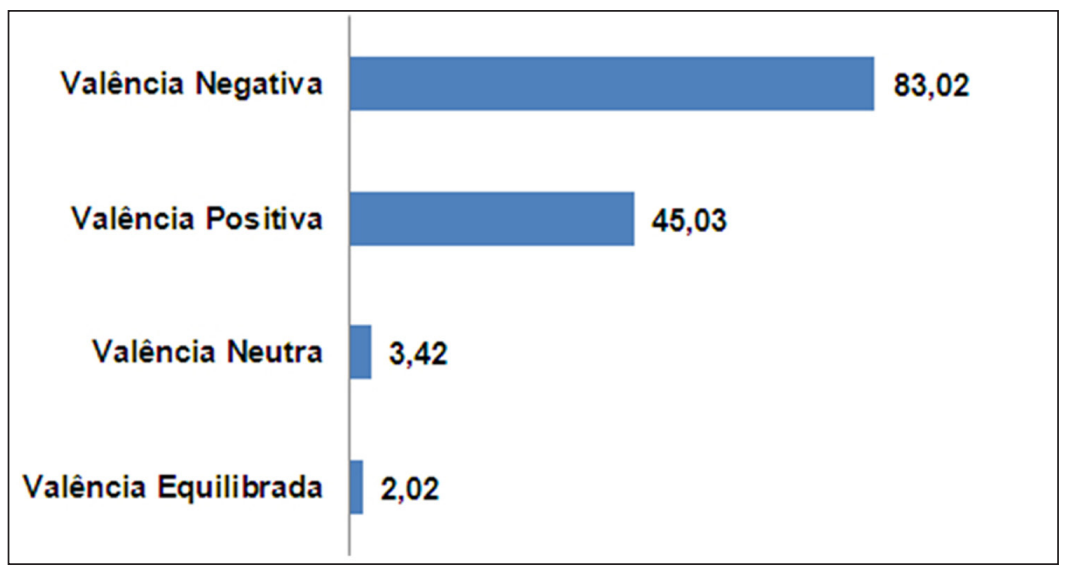

Figura 2 - Valência das matérias veiculadas no Jornal Nacional (2011), conforme o tempo de duração em minutos

Para se ter uma ideia da proporção da duração das reportagens com valência negativa para o tema saúde pública, os 83'02" representam 62,19\% do total do tempo dedicado ao assunto (133'49') pelo telejornal. Esse número significa quase o dobro do tempo dedicado ao sistema público de saúde, com valência positiva: 45'03'", responsáveis por 33,73\% da duração total. As valências neutras somam apenas 3'42', ou $2,56 \%$ do tempo total; e as valências equilibradas somente $2^{\prime} 02^{\prime}$ ou, $1,51 \%$ de todo o tempo, dedicado ao tema saúde pública. Esses dados indicam que o tempo com valência negativa é maior e, portanto, os sentidos operados nas matérias ganham maior destaque que os positivos, conferindo ao tema saúde pública, uma visibilidade predominantemente negativa.

Na existência humana, com a impressão das marcas da vida, a fala (a narrativa jornalística pode ser considerada uma fala) torna-se uma fala mítica e, neste sentido, Barthes a reconhece na perspectiva do signo, podendo ser linguístico (escrito) ou 
por representação como a fotografia, a publicidade, o cinema, o esporte, entre outros suportes que fornecem interpretação a partir da linguagem.

A fala mítica é formada por uma matéria já trabalhada em vista de uma comunicação apropriada: todas as matérias-primas do mito, quer sejam representativas quer gráficas, pressupõem uma consciência significante, e é por isso que se pode raciocinar sobre eles independentemente da sua matéria."

(Barthes, 1993, p. 132)

Se a vida fornece elementos para a construção do mito, qualquer elemento significativo (ou não) pode conter aspectos capazes de alçar um objeto à condição mitológica, principalmente se estiver associado à cultura midiática, ou seja, os veículos de comunicação de massa são capazes de construir a imagem de grupos, segmentos ou áreas da sociedade. "Se é a comunicação que constrói a realidade, quem detém a construção dessa realidade detém também o poder sobre a existência das coisas, sobre a difusão das idéias, sobre a criação da opinião pública" (Guareschi, 1993, p. 15).

\section{Falas míticas}

O jornalismo factual, o que baseia a sua notícia no fato/acontecimento, publica, geralmente, informações de fatos negativos que repercutem na sociedade. Isso fica evidente nas reportagens sobre a saúde pública que tem, nos problemas e na deficiência do sistema, o seu principal enfoque noticioso. 
Em reportagem do dia 16/04/2011, o JN abordou as grávidas que "enfrentam superlotação em maternidades públicas de Aracaju”. O apresentador Alexandre Garcia destaca que "O JN no Ar mostrou ontem a falta de vagas em maternidades e UTIs de Alagoas. Hoje você vai ver que o estado vizinho, em Sergipe, sofre com o mesmo problema". A repórter Carla Suzanne, afirma: "Corredores lotados, gente em busca de atendimento. Daiane veio da Bahia até Aracaju, são 200 quilômetros" (Suzanne, 16/04/2011). A entrevistada confirma que onde mora não tem maternidade.

Neste trecho, as falas "falta de vaga em maternidades", "sofre com o mesmo problema", "corredores lotados" são falas selecionadas e ajudam a construir ou reforçar o sistema público de saúde como ineficiente e, assim, criando um mito sobre o Sistema Único de Saúde. A fala enquanto unidade linguística é reforçada pela fala imagética. Em televisão, a imagem é complementada pelo texto e vice-versa. Um reforça o outro, construindo um discurso em comum.
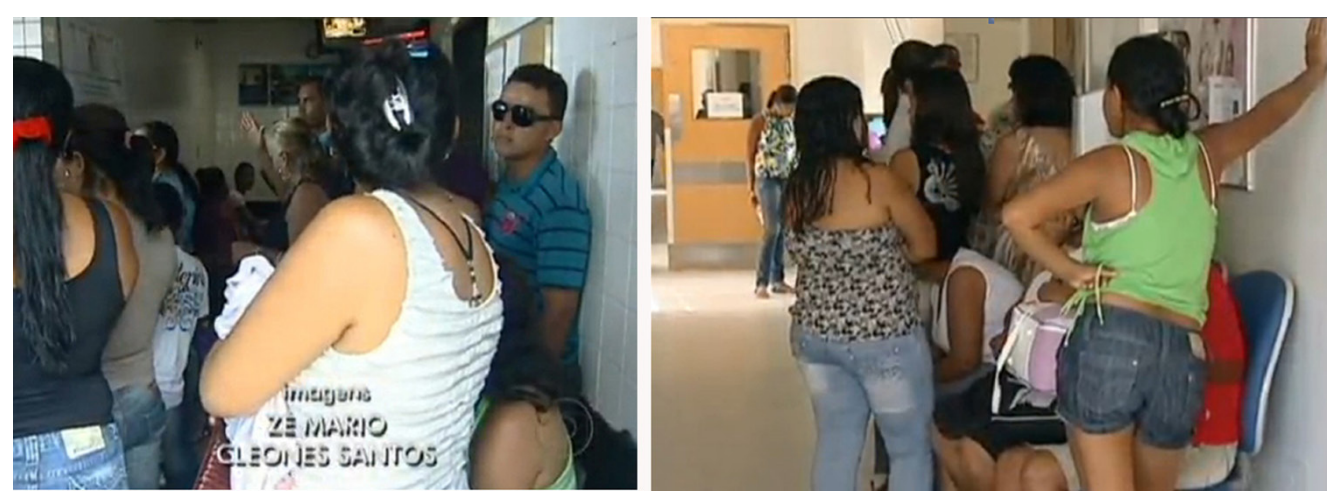

Figura 3 - Pacientes esperam atendimento em maternidade de Sergipe.

Reprodução JN 16/04/2011 
Na Fig. 3, a imagem do JN destaca ângulos com salas de espera cheias de pacientes. As imagens confirmam a situação de superlotação das unidades de saúde com, a consequente falta de atendimento, ao usuário da saúde pública. Ressaltando outros fatos, a repórter afirma que "Pacientes de estados como Bahia e Alagoas disputam leito com as gestantes de Sergipe" (Suzanne, 16/04/2011). A usuária Maria de Lourdes de Araújo confirma: “Lá a maior parte das pessoas vem/são transportadas pra cá. Não tem o atendimento que aqui tem" (Suzanne, 16/04/2011).

Para a reportagem, o problema não é a falta de organização dos serviços públicos de saúde em diferentes municípios e estados, mas o fato de, uma parcela da população, buscar atendimento em outra localidade. Essa fala contribui para o mito de que usuários de um local roubam atendimento de outras pessoas no seu próprio local de origem.

Segundo a reportagem, 30\% dos atendimentos das maternidades de Aracaju são de estados vizinhos. Esse dado é corroborado pelo secretário da Saúde de Sergipe, Antonio Carlos Guimarães. "Nesse momento não temos a condição de atender a essa demanda. Nós estamos atendendo a demanda interna do nosso estado, já com certa dificuldade porque a nossa rede passa por readequação física" (Suzanne, 16/04/2011).

Ainda com falas que reforçam as deficiências do SUS, que existem e não são negadas neste trabalho, para garantir o atendimento ao usuário, a reportagem destaca que "cinco hospitais regionais funcionam como maternidade, mas, segundo o Sindicato dos Médicos, apenas dois atendem plenamente." A repórter informa que "os outros dois apresentam problemas estruturais", citando o caso da unidade Nossa Senhora do Socorro, na grande Aracaju. A unidade deveria atender, por mês, 250 gestantes, "o que não acontece porque o centro cirúrgico está fechado. A reforma do prédio já dura quase dois anos." Na Fig. 4, a fachada da unidade em reformas. A imagem mostra o prédio ao fundo, destacando uma construção abandonada ao lado, com mato na calçada e 


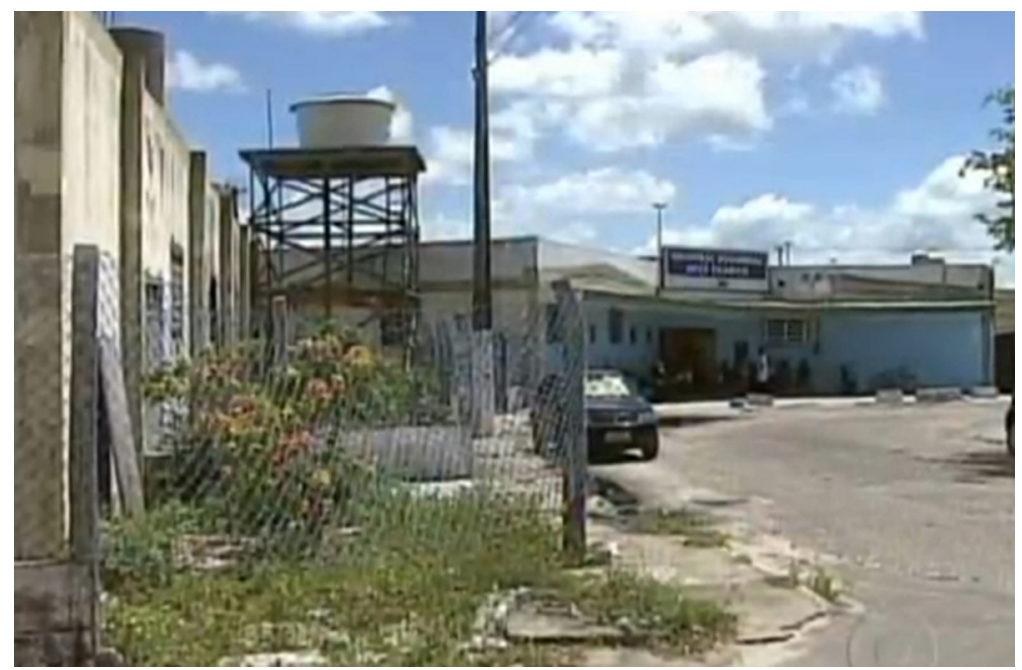

Figura 4 - maternidade na Grande Aracaju.

Reprodução JN 16/04/2011 entulho de construção. A imagem, uma fala visual, aumenta ainda mais a percepção de abandono da saúde pública em Aracaju.

Entrevistado pela reportagem, José Menezes, presidente do Sindicato dos Médicos de Sergipe, corrobora a fala de abandono. "Nós estamos aqui em reforma, a população procura pensar que tem um hospital, porque isso não pode ser considerado um hospital." (Suzanne, 16/04/2011).

Para Barthes, a fala mítica é uma fala escolhida na própria história e, por isso, não é de se estranhar que essas falas voltem, em um novo contexto, recheadas de novos significados. Por isso, é recorrente o tema saúde pública estar associado à ineficiência no atendimento ao usuário do sistema.

A reportagem Crianças que dependem de cirurgia enfrentam longa espera no Piauí, de 22/07/2011, destaca a dificuldade de conseguir uma cirurgia pediátrica em hospitais do Piauí. O apresentador inicia o texto afirmando que "Crianças que dependem de uma cirurgia no Piauí estão enfrentando uma longa fila de espera".

A repórter Neyara Pinheiro inicia a reportagem relatando o caso da menina Ana Vitória, que tem um cisto próximo da coluna e que "a mãe da menina não consegue marcar a cirurgia" (Pinheiro, 22/07/2011). A repórter não cita qual a 
doença que acomete a criança, nem a gravidade do problema, que exige uma intervenção cirúrgica. A repórter entrevista a mãe que revela impotência diante do problema. Com voz embargada, a mulher afirma: "Às vezes, ela se queixa de dor e eu não posso fazer nada. Eu digo - Oh minha filha, mamãe não pode fazer" (Pinheiro, 22/07/2011). A falta de atendimento é imageticamente representada pela sala de espera lotada. Na Fig. 5, crianças aguardam sentadas até serem chamadas para atendimento.

Figura 5 - Crianças em sala de espera em hospital do Piauí. Reprodução JN 22/07/2011

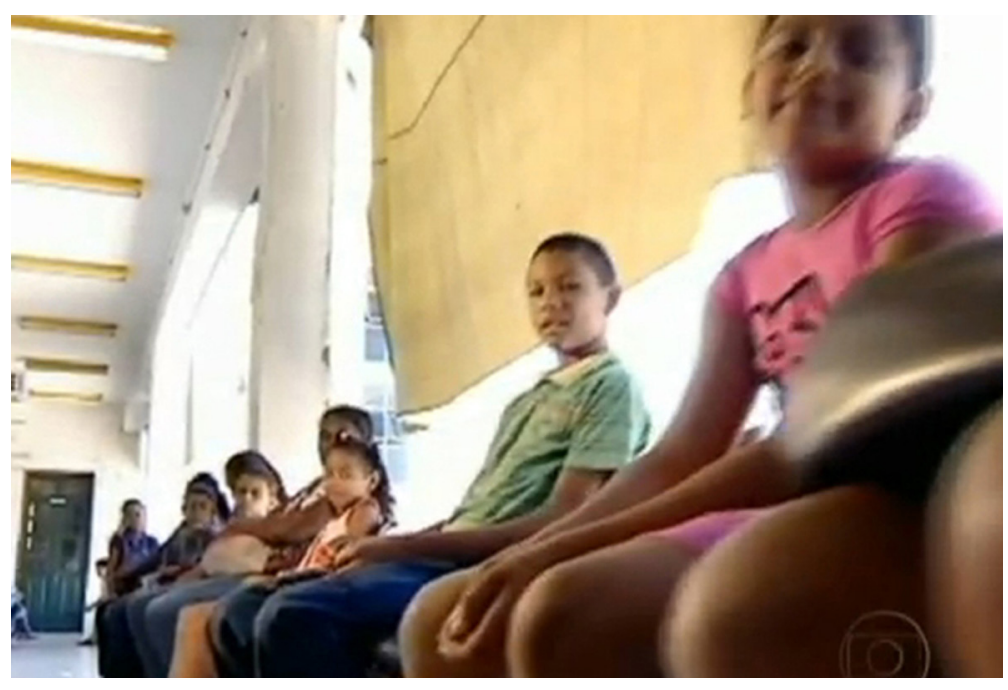

Se, por um lado, a superlotação é usada pelos veículos de comunicação para representar a falta de atendimento ao usuário de saúde, por outro lado, o vazio também é representativo, para mostrar a falta de atendimento, já que a espera é longa. A Fig. 6 revela essa intencionalidade. 
A sala de espera vazia revela que o paciente do SUS está sem atendimento. Ambas figuras são falas imagéticas que reforçam o sistema público de saúde como deficitário. $\mathrm{O}$ texto da reportagem ainda destaca que o hospital Lucídio Portela, único a realizar cirurgias pediátricas, "há quase quatro meses enfrenta uma das piores crises desde a sua fundação, em 1986" (Pinheiro, 22/07/2011). Segundo a reportagem, os médicos deixaram de realizar cirurgias eletivas, aquelas em que não há risco de morte, e, a cirurgia pode ser agendada com antecedência.

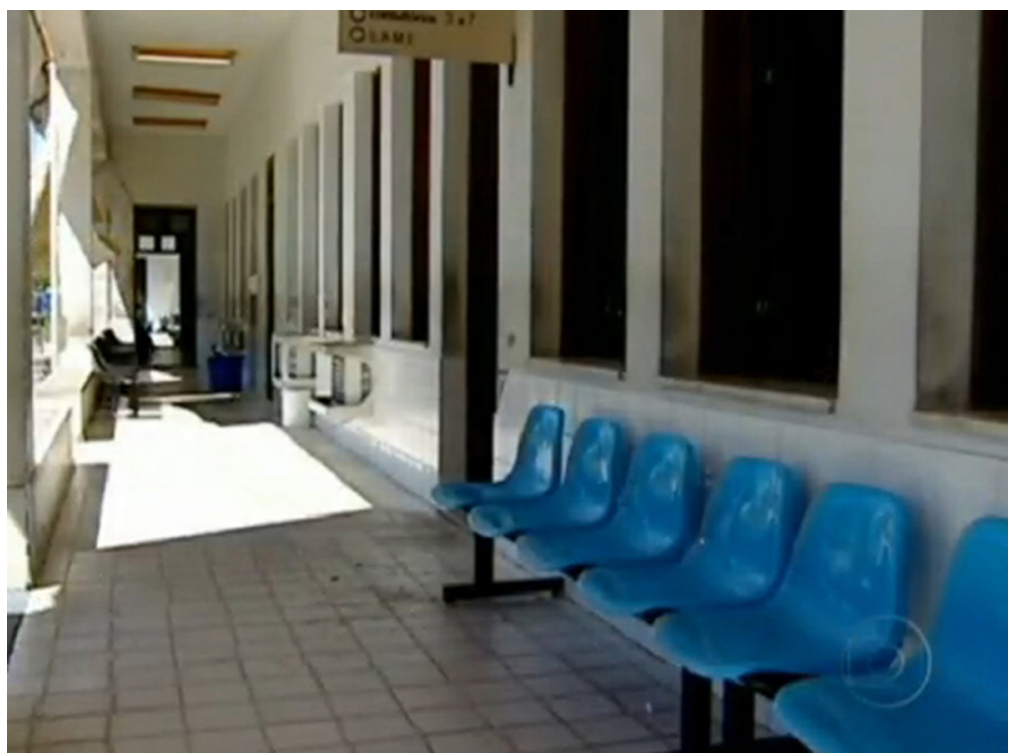

Figura 6 - Sala vazia em hospital do Piauí. Reprodução JN 22/07/2011

A repórter afirma que os médicos "alegam que não há condições de trabalho". O cirurgião pediátrico Fernando Carvalho confirma. "Um dia nós chegamos para operar e não tinha gase. Aí meu irmão, se não tem gase, nós chegamos ao fundo do poço" (Pinheiro, 22/07/2011).

Outro cirurgião pediátrico entrevistado pela reportagem, Edinaldo Miranda, caracteriza como "um número assustador" o número de crianças piauienses em fila de espera por uma cirurgia: 1.600. "A capacidade deste hospital, nós levaríamos de 8 a 10 meses para operar só os pacientes que estão na fila de espera" (Pinheiro, 22/07/2011). No entanto, a reportagem não detalha as cirurgias que 
as crianças precisam fazer nem o que a falta dela pode acarretar na vida dos pacientes crianças do Piaui.

O mito não é um elemento estanque e que, depois de constituído, terá vida longa ou, existência eterna. Barthes (1993, p. 132) afirma que não há manifestação conjunta de todos os mitos, de forma simultânea. "[...] certos objetos permanecem cativos da linguagem mítica durante um certo tempo, depois desaparecem, outros substituem-no, acedendo ao mito."

Nesse contexto, expressões como superlotação, longa fila de espera, demora no atendimento, falta de atendimento, peregrinação em busca de atendimento são falas selecionadas pelo telejornalismo que as associam à deficiência do sistema público de saúde.

O Jornal Nacional utiliza essas falas em várias reportagens, dando ênfase à superlotação, à falta de atendimento, em pacientes esperando procedimentos, internados em corredores ou em bancos do saguão de espera de unidades hospitalares. No dia 21/10/2011, a reportagem do JN esteve no Mato Grosso para mostrar o atendimento em hospitais de Várzea Grande, na grande Cuiabá. A matéria é de Paulo Renato Soares (Fig. 7).
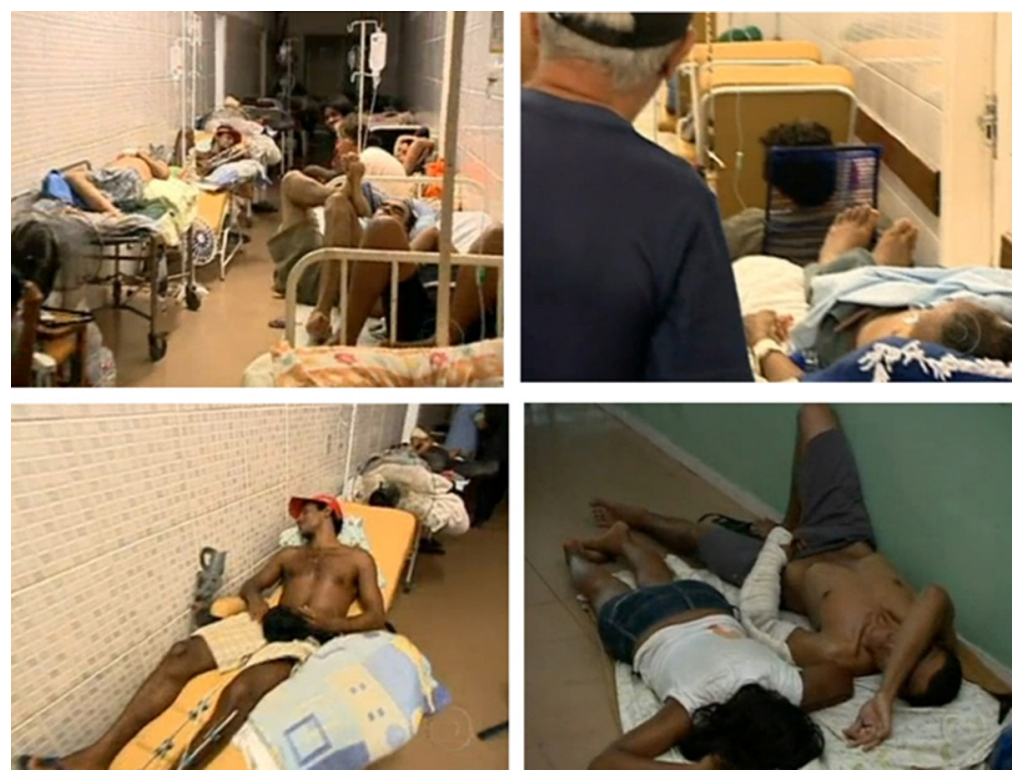

Figura 7 - Imagens matéria JN - 21/10/2011 
O repórter mostra que o hospital atende, inclusive, pacientes da capital, cujo prontosocorro, suspendeu o atendimento de urgência porque a área foi interditada, depois que parte do teto desabou por causa de uma chuva. Mais uma vez, a reportagem expõe pacientes internados em corredores, esperando atendimento em colchões improvisados no chão.

As cenas enfatizam a superlotação dos hospitais, que não comportam mais receber pacientes. Os signos presentes no contexto imagético são a fila, a demora e a espera pelo atendimento. Ao inscrever signos como esses nas cenas da reportagem, o Jornal Nacional destaca o sofrimento para quem precisa do serviço público, e, a ineficiência do atendimento governamental. "[...] pode-se dizer que o valor de um signo pode ser determinado por aquilo que está à volta do signo, em seu entorno. Pode-se dizer também que o valor depende da situação recíproca dos elementos da língua" (Coelho Netto, 2003, p. 23). Outras reportagens, também, ressaltam a falta de estrutura para atender pacientes no serviço público (Fig. 8).
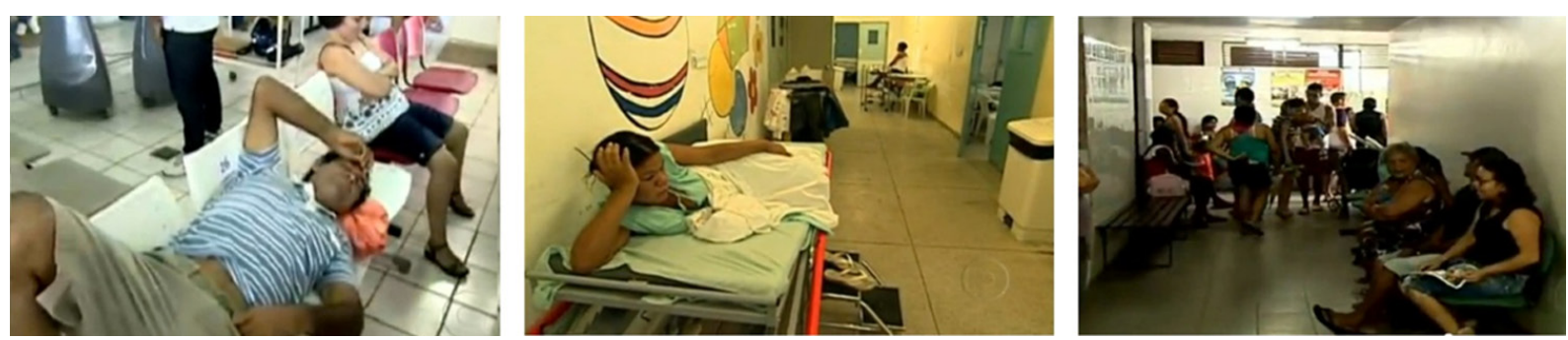

Figura 8 - Imagens (Acre) JN - 26/01/2011; (Alagoas) JN - 15/04/2011; (Pará) JN - 24/08/2011

No dia 26/01/2011 foi veiculada matéria sobre a deficiência no atendimento a pacientes vítimas de uma epidemia de dengue em Rio Branco, capital do Acre. A 
matéria é, também, de Paulo Renato Soares. No dia 15/04/2011, a reportagem do JN mostrou a superlotação nas maternidades de Alagoas, em matéria de Bette Lucchese. No dia 24/08/2011, o repórter André Luiz Azevedo e a equipe do JN estiveram em Belém/PA, para mostrar a situação dos atendimentos nos hospitais da capital paraense.

Portanto, o mito está atrelado de tal forma à linguagem, que precisa desta, para a sua constituição, ainda mais, se considerada a linguagem como a forma externa do pensamento.

A mitologia [...] é uma necessidade inerente à linguagem, se reconhecemos nesta a forma externa do pensamento: a mitologia é, em suma, a obscura sombra que a linguagem projeta sobre o pensamento, e que não desaparecerá enquanto a linguagem e o pensamento não se superpuserem completamente: o que nunca será o caso."

(Müller apud Cassirer, 2003, p. 19)

É interessante perceber como, em até reportagens com valência positiva, há associação negativa ao SUS, reforçando o mito de ineficiência (enquanto fala mítica) do serviço público. No dia 01/09/2011, o JN destacou em sua edição, que a "Rede pública oferece tratamentos a fumantes que queiram deixar o vício".

A reportagem de André Luiz Azevedo mostra dados positivos de combate ao tabagismo. O texto da passagem do repórter: 
A guerra contra o cigarro é difícil - todo mundo sabe. Por isso tem muitas frentes, muitas táticas, mas a boa notícia é que ela está sendo vencida. Além de quem nunca fumou, hoje no Brasil, já há mais ex-fumantes do que fumantes. E todo dia em algum lugar do país surgem grupos como esse. São pessoas que querem aprender como vão parar de fumar."

(Azevedo, 01/09/2011)

A Fig. 9 consiste em uma fala imagética que reforça o texto linguístico do repórter: "Além de quem nunca fumou, hoje no Brasil, já há mais ex-fumantes do que fumantes" (Azevedo, 01/09/2011).

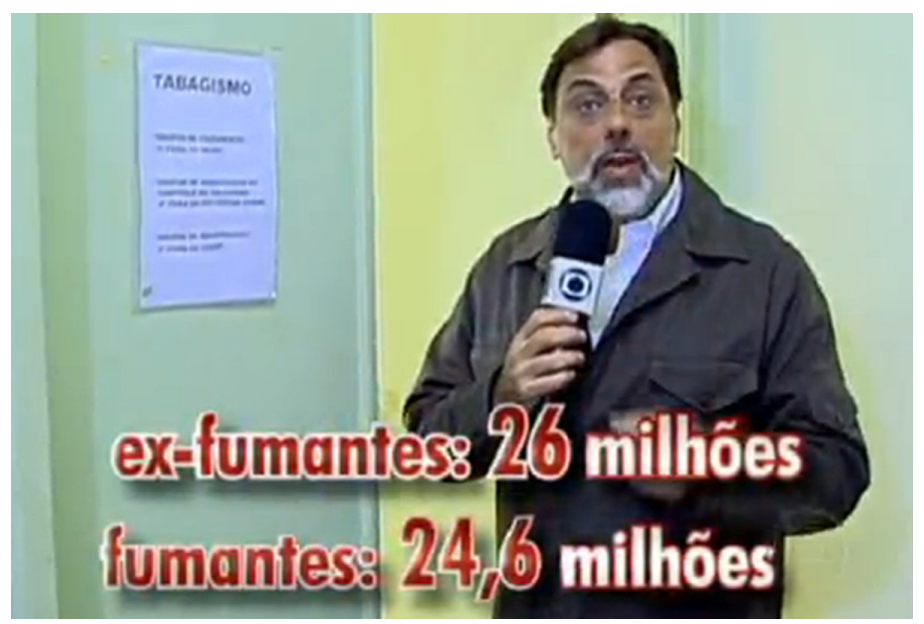

Figura 9 - Repórter André Luiz Azevedo.

Reprodução JN 01/09/201 1 
A imagem mostra que os fumantes (24,6 milhões) estão em número menor que os ex-fumantes (26 milhões). A guerra que está sendo vencida passa por grupos de apoio, a partir do Programa de Combate ao

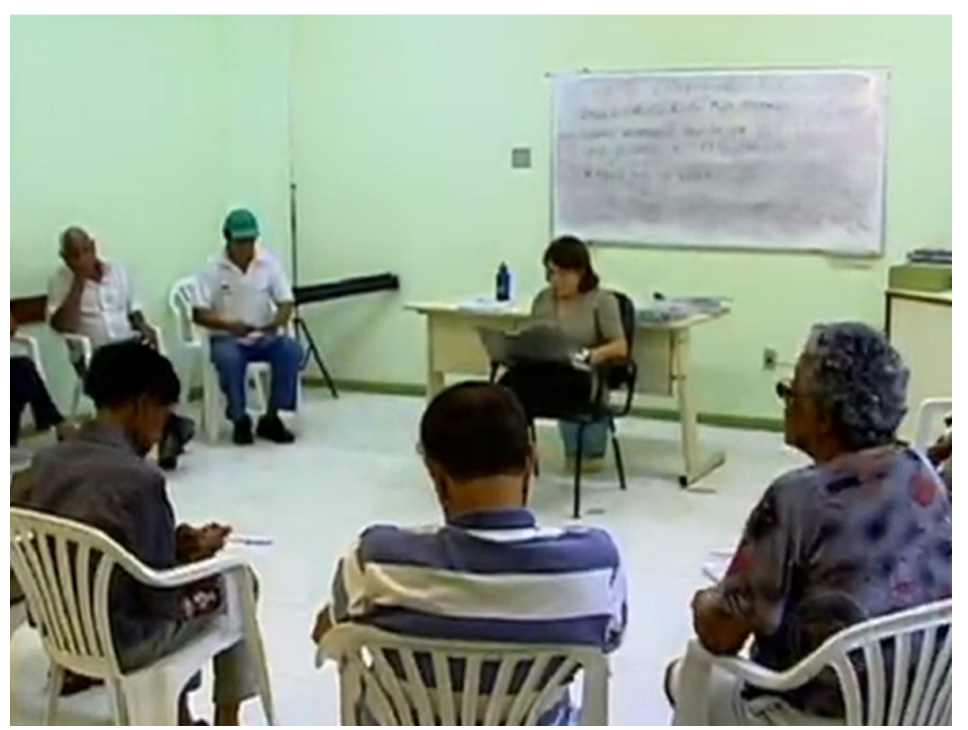

Figura 10 - Grupo de combate ao tabagismo no Rio de Janeiro. Reprodução JN 01/09/2011

combater o vício". No entanto, há uma fala negativa sobre o projeto: "o programa oferecido pelo Sistema Único de Saúde, só existe em cerca de 900 dos mais de 5 mil municípios do país" (Azevedo, 01/09/2011). O programa mesmo sendo importante ainda é insuficiente para atender o Brasil. A fala consiste numa mensagem que reforça o caráter de ineficiência, constatado nos exemplos anteriores. Neste sentido, Barthes afirma que o mito é um sistema de comunicação. 
[...] o que deve estabelecer solidamente desde o início é que o mito é um sistema de comunicação, é uma mensagem. Eis por que não poderia ser um objeto, um conceito, ou uma ideia: ele é um modo de significação, uma forma."

(Barthes, 1993, p. 131)

A linguagem, responsável por produzir a fala mítica que cria, sustenta, ou recria, os mitos, é corroborada por Usener apud Cassirer (2003, pp. 29-30), para quem a linguagem, entre todas as formas de expressões "aos poucos produz uma expressão, que logo estende seu domínio sobre um número sempre crescente de casos, até que, por fim, se presta a abranger todos eles e pode tornar-se conceito genérico".

Nesta complexidade estrutural, o mito compõe - segundo Barthes - um sistema semiológico, sendo um fragmento desta ciência que estuda os signos, e, que postula uma relação entre os significantes e os significados, não em um processo de igualdade, mas de equivalência. Barthes atesta que buscar a significação é recorrer à semiologia.

Não quero dizer com isto que a semiologia cubra igualmente todas estas pesquisas: elas têm conteúdos diferentes. Mas têm um estatuto comum, são todas elas ciências dos valores; não se contentam em circunscrever o fato: definem-no e exploram-no como um valor de equivalência."

(Barthes, 1993, p. 133)

O autor transpõe alguns nomes da semiologia para o que ele chama de sistema mítico. O significante da semiologia é nomeado como sentido; o significado é 
transformado em conceito e, o signo, em significação. Para tanto, faz-se necessário entender a relação entre a forma e o conceito, já que, o significante do mito, para o autor, apresenta-se de forma ambígua, ou seja, pleno e vazio, ao mesmo tempo.

Enquanto sentido, o significante já postula uma leitura [...] está completo, postula um saber, um passado, uma memória, uma ordem comparativa de fatos, de ideias e de decisões [...] Tornando-se forma, o sentido afasta a sua contingência, esvazia-se, empobrece, a história evapora-se permanece apenas a letra."

(Barthes, 1993, p. 139)

Transformar o social, o cultural, o ideológico em natural, é um processo que passa, também, pelas relações de poder, em que os veículos de comunicação de massa ocupam, lugar de excelência.

\section{Considerações finais}

Os fatos ao serem contados são reconstituídos, ou seja, são representados a partir da realidade. A reconstituição dos fatos, não são os fatos em si, mas a maneira como o Jornal Nacional vê a saúde pública. O papel do telejornalismo na construção de sentidos é incontestável, visto a sua capacidade de pautar debates, agendar discussões e influenciar a formação da opinião pública.

Nesse contexto, o mito é construído social e historicamente, num contexto de interação - inclusive ideológica - entre indivíduos e segmentos da sociedade, ou seja, ele é produzido na e para a realidade. O signo linguístico e visual torna-se, portanto, 
a fala cuja matéria cria os mitos, sejam eles primários, ou roubados de outros mitos. Neste sentido, a sociedade contemporânea é pródiga em produzir e reproduzir falas que originam os mitos que se mantêm "no ar" conforme o poder de sustentação das próprias falas.

É necessário considerar o papel da cultura midiática (representada pelos veículos de comunicação de massa) que apresenta, constantemente, a matéria-prima para a formação de mitos na sociedade contemporânea. A velocidade na produção e na difusão de informações e imagens é responsável por fornecer elementos para a criação de mitos instantâneos, efêmeros, numa fórmula permanente: sai um mito e entra outro da mesma categoria, consumido sem consciência, ou reflexão.

Na cultura midiática, os mitos nascem e morrem, diariamente. E a necessidade por novos mitos parece não ter fim, principalmente, se considerada a perspectiva do espetáculo. Mudam-se as pessoas, e, os mitos continuam presentes, afirmando e reafirmando, a sua condição na existência humana. E enquanto o espetáculo dominar a cena na produção das falas dos meios de comunicação, o mundo continuará a ser um consumidor de mitos, inclusive, sem se dar conta dessa condição.

Nesse sentido, as falas sobre a saúde pública no Jornal Nacional constroem um mito de ineficiência, associando-lhe incapacidade de atender com qualidade aos usuários do Sistema Único de Saúde. Expressões como superlotação, falta de atendimento, demora no atendimento, longa fila de espera e peregrinação sustentam as falas míticas que corroboram a imagem do sistema público de saúde.

\section{REFERÊNCIAS}

AZEVEDO, André Luiz. Rede pública oferece tratamentos a fumantes que queiram deixar o vício. Jornal Nacional, Rede Globo, Rio de Janeiro, 01 set. 2011.

BARTHES, Roland. Mitologias. 9. ed. Rio de Janeiro: Bertrand Brasil, 1993. 
CAMPBELL, Joseph. As transformações do mito através do tempo. São Paulo: Cultrix, 1990.

CASSIRER, Ernst. Linguagem e mito. 4. ed. São Paulo: Perspectiva, 2003.

CASTILHO, Ataliba T. de. A língua falada no ensino de português. 6. ed. São Paulo: Contexto, 2004.

COELHO NETTO, Teixeira. Semiótica, informação e comunicação: diagrama da teoria do signo. São Paulo: Perspectiva, 2003.

ELIADE, Mircea. Mito e realidade. São Paulo: Perspectiva, 2010.

FLUSSER, Vilém. Filosofia da caixa preta: ensaios para uma futura filosofia da fotografia. Rio de Janeiro: Relume Dumará, 2002.

GUARESCHI, Pedrinho. A realidade da comunicação - visão geral do fenômeno (13-22). In: GUARESCHI, Pedrinho. Comunicação \& Controle Social. Petrópolis: Vozes, 1993.

PINHEIRO, Neyara. Crianças que precisam de cirurgia no PI enfrentam fila de espera. Jornal Nacional, Rede Globo, Rio de Janeiro, 22 jul. 2011.

PORCELLO, Flávio; GADRET, Débora Lapa. A TV no Brasil: influência política e o discurso de poder. In: VIZEU, Alfredo; PORCELLO, Flávio; COUTINHO, Iluska (Orgs.). 60 anos de Telejornalismo no Brasil: história, análise e crítica. Florianópolis: Insular, 2010. pp. 215-231.

SUZANNE, Carla. Superlotação é registrada em maternidades de Aracaju (SE). Jornal Nacional, Rede Globo, Rio de Janeiro, 16 abr. 2011.

VIZEU, Alfredo; CORREIA, João Carlos. A construção do real no telejornalismo: do lugar de segurança ao lugar de referência. In: VIZEU, Alfredo (Org.). A sociedade do telejornalismo. Petrópolis: Vozes, 2008. pp. 11-28.

\section{Endereço dos autores:}

Florentina das Neves Souza <flora@uel.br>

Universidade Estadual de Londrina - Centro de Educação Comunicação e Artes - Departamento de Comunicação

Rodovia Celso Garcia Cid, PR 445 Km 380 - Campus Universitário

CEP 86051-990, Londrina, PR, Brasil

Reinaldo César Zanardi <reinaldo.zanardi@unopar.br>

Universidade Norte do Paraná - Centro de Ciências Empresariais e Sociais Aplicadas - Departamento de Comunicação Social Rodovia Celso Garcia Cid, Km 377 - Jardim Burle Max

CEP 86047-500, Londrina, PR, Brasil 